\title{
RESENHA EXPERIMENTAL
}





\section{EXPERIMENTO / MATERIAL HEINER MÜLLER}

Heiner Muller por Mark Lammert

\section{Maria Cláudia Curtolo Silvio Ricardo Sanaya}

\footnotetext{
1 Mestrandos em Sociologia pela Universidade Estadual de Campinas (Unicamp). mariaclaudiacurtolo@gmail.com, sloswy@gmail.com. Dedicado a Laymert Garcia dos Santos c a nossos encontros de quinta.
} 
1.

\section{ÁlBUM DE FAMÍLIA}

Curriculum 1956 saxão nascido em 1929 de costureira de família abastada que não accita casamento humilde e secretário de administração PAI É UMA PARTEIRA DA hISTÓRIA preso preventivamente em 1933 pelos nazis como funcionário do SPD levado para o campo de concentração QUATRO ANOS SEU PRIMEIRO PESADELO hISTÓRICO A CENA INAUGURAL DE SEU TEATRO SUA PRIMEIRA TRAIÇÃO FINGIR ESTAR DORMINDO. Pai liberado da prisão fraco franzino que antes não pulou aquela grade PRIMEIRA IMAGEM DE SEU MURO expulso do distrito desempregado até 1938 quando GAROTO ESCREVE SUA SEGUNDA TRAIÇÃO EM FORMA DE ENSAIO ELOGIO ESCOLAR MEU PAI AJUDOU A DIZER QUE É BOM QUE O FÜHRER CONSTRUA A AUTOBAHN FONTE DE SEU FUTURO EMPREGO. Na possessão do trabalho prisão preventiva cm 1941 COMUNISTA liberação após quatro anos como prisioneiro de guerra chefe de departamento na prefeitura de Waren secretário provincial do SED para Cultura Universidade etc prefeito de Frankenberg em 1947 excluído do SED cm 1951 TITOÍSTA desde então na Alemanha Ocidental internado como suspeito no próximo campo de concentração interrogado pelos Aliados NAZISTA. Uma bactéria o carrega para o hospital isolado onde o FILHO O VISITA DO OUTRO LADO DA PORTA DE VIDRO SEGUNDA IMAGEM DE SEU MURO. Pais ESCOLHEM FUGIR para a Alemanha Ocidental ironia do destino pai tratar do pagamento da pensão de viúvas nazis. Já expurgada do ventre a hISTÓRIA MAQUINA A CARNE HERDEIRA estudo interrompido pelo serviço civil obrigatório do Reich MÍOPE NÃO ATIRA BEM um instante na guerra fascínio por tanque blindagem prisão putrefação velocidade fugindo dos russos em busca da rendição aos americanos nunca viu sequer um humano morto e A GUERRA INCRUSTA A EXPERIÊNCIA. Trabalho na prefeitura de Waren seguido da Biblioteca de Frankenberg LADRÃO DE LIVRO escritor autônomo cm 1951 FICA NA ALEMANHA ORIENTAL sua segunda máquina paranóica sua segunda ditadura. 
2.

\section{ANJO DA HISTÓRIA/ NECROFILIA É O AMOR AO FUTURO}

Jornalista redator crítico literário escreve por troca de dinheiro reprodução de uma existência amplificada no bar na bebida no fumo na arte. Teatrólogo dramaturgo poeta fiel à Alemanha Oriental desde suas primeiras peças nos auspícios do MURO DO TEMPO QUE FRATURA A ALEMANHA RFA RDA ENTRANHAS ABERTAS CORAÇÃO DO SÉCULO XX encarniça enraivece a máquina paranóica sendo perseguido reconhecido TRAIDOR HERÓI DA RDA ANTIHUMANISTA ANTICOMUNISTA REALIZADOR DE GRANDE OBRA DO SOCIALISMO REAL prêmio Heinrich Mann prêmio de Dramaturgia Mülheim prêmio Georg Büchner prêmio Nacional da RDA prêmio Kleist prêmio Europa de Dramaturgia blá CONTRA-REVOLUCIONÁRIO PERIGOSO À SEGURANÇA DO ESTADO NEVRÁLGICO. Sua arte FACA sua questão FERIDA POR QUE A RDA NÃO SE REGISTRA COMO ALTERNATIVA AO CAPITAL E SIM SEU CONCORRENTE sua linguagem citação de Hölderlin em funcionamento pois SUAS PALAVRAS SÃO ASSASSINATO maquinam tragédias gregas MAIS-VALIAS DE HISTÓRIA que passam cortando pelos que no teatro realidade suspeitam percebem sabem apostam no SOCIALISMO SOCIALIZAÇÃO DA POBREZA no mau funcionamento da máquina social nas contradições. Seu material vem da carne podre dos mortos SONHOS PROBLEMAS IDEIAS que aí moravam não passam pela mesma decomposição COMÊ-LOS para vomitar as partículas pedaços resíduos vivos e submetê-los à pressão da experiência à destruição à transformação desnudar a pele a superfície IR ATÉ O OSSO estrutura para escrever mais do que sabe transhistoricamente $\mathrm{O}$ DESTINO É A HISTÓRIA NECROFILIA VIVISSECÇÃO UTOPIA. Nietzsche veio para ele antes de Marx Shakespeare é sua obsessão Kleist e a busca da face do sentido da guerra é sua potência no palco TEATRO DE GUERRA MESMO QUE NO CAPITALISMO MESMO QUE NO SOCIALISMO REAL MESMO QUE NO ESPAÇO VAZIO DESENRAIZADO DO COMUNISMO o caráter destrutivo e as teses da 
história de Benjamin marcadas em seu corpo giradas em sua escrita Kafka o auto-selecionado NA MENTE prisioneiro do campo de concentração mostra que A POLÍTICA É PRINCÍPIO DE SELEÇÃO Dostoievski RASKOLNIKOV NO PEITO A GRAÇA A PUTA Ernst Jünger menino mau sorriso selvagem da literatura amoral o interessa O ASSALTO NA PRIMEIRA GUERRA SURPRESA TÉCNICA É ALÍVIO LIBERAÇÃO DA TENSÃO Artaud a tortura a crueldade o horror SEUS TEXTOS LIDOS A PARTIR DAS RUÍNAS DA EUROPA SÃO CLÁSSICOS Brecht e sua inveja do fragmento Fatzer não de seu simplismo O HOMEM É O INIMIGO E TEM DE SER ANIQUILADO Fatzer percebe e caga para a ordem do mundo uma essência cheiro de experiência pós-burguesa e a História Alemã A EXPERIÊNCIA ALEMÃ É FUNDAMENTAL para percepção das operações tresloucadas da grande máquina. Ele é um outsider em Deutschland PRIVILEGIADO DIZEM PODE FAZER O QUE QUER os ocidentais gostam dele apreciam esteticamente seu teatro um sismógrafo que na arte capta MUITO MAIS rapidamente ANOS LUZ os acontecimentos as viradas as potências sua mensagem espalhar pelos muros o espanto $\mathrm{A}$ APARIÇÃO ESPERANÇA DO NOVO enfrentando NO BRANCO DOS OLHOS recalques máscaras do destino ELE ESTÁ ESCREVENDO A TRAGÉGIA CONTEMPORÂNEA.

3.

HUMANO POTÊNCIA / ELECTRA AMORDAÇADA

PENSAMENTO E ARTE SÃO FUNDAMENTALMENTE CULPÁVEIS o sismógrafo registra a tecnologia se atualizando nos séculos XX e XXI como desrealização da realidade teatralização política a TECNOCIÊNCIA como destruição do contato. ASSASSINATO GUERRA CIVIL ao invés de treinamento preparação prontidão os últimos refúgios linhas de fuga do humano da mecanização de nenhuma dor GUERRA COMO POTÊNCIA É CONTATO CONFLITO TEMPO LIVRE EXPERIÊNCIA COLETIVA. Humanismo é barbárie exclusão controle

Temáticas, Campinas, 18(35/36): 205-210, jan./dez. 2010 
seleção. Razão Iluminada modus operandi tecnociência é lógica da máquina redução do homem à matéria-prima AUSCHWITZ O ALTAR DO CAPITALISMO estratégia de aceleração total cconômica e tecnológica operando MORTE ÀS MINORIAS que emperram a engrenagem. A formiga como PERFEIÇÃO do homem machine no capitalismo o HUMANO é desordenado erro ruído inimigo fator de perturbação que deve desaparecer QUANTO MAIS MOSCA MELHOR. NÃO à indagação moral do terrorismo MATAR COM HUMILDADE. Não se delega CIVILIZADAMENTE ao Estado matar com as próprias mãos. Unificação alemã TORPOR POLÍTICO A QUEDA DE UM DE SEUS MUROS MAS AINDA EXISTEM MUITOS direita amarela esquerda vermelha mostarda ketchup a salsicha é a mesma OS MATERIAIS FAZEM O MERCADO OS EXECUTIVOS SÃO OS HERÓIS O TEATRO VALE O DEUTSHMARK. OFELIA/MEINHOF/ELECTRA seu grito na boca cheia de sangue VIVA O ÓDIO O DESPREZO A INSURREIÇÃO A MORTE em suspensão o que por enquanto sobram são brigas de bar pancadarias de estádio. Por quanto tempo já que HISTORY IS MORE THAN POLITICS os mortos não morrem nunca, ANJO SEM SORTE BATA SUAS ASAS ANUNCIE SEU VÔO.

4.

\section{SHAKESPEARE OBSESSĀO / DIFERENÇA}

Quando inspiração esperança diminuem parecem desaparecer o trabalho sobre Shakespeare toma efeito de verdadeira transfusão de sangue. Shakespeare é reserva de temas que atinge seus ossos veias vísceras fluídos secreções. Sua SHAKESPEARE FACTORY SUA USINA parte Macbeth segundo Shakespeare (1971) parte Hamlet-Máquina (1977/1989) parte Anatomia Titus queda de Roma um comentário de Shakespeare (1984). Macbeth é questão de açougue as maquinações cruentas VIOLÊNCIA INCOMENSURÁVEL do poder do Estado do soberano SUSTENTAÇÃO SOBRE CADÁVARES IMPOSTORES OPOSITORES CAMPONESES 
SOLDADOS operários intelectuais VONTADE DE PERMANÊNCIA do açougue carnes a massacrar tormentar gozar AMANHÃ E AMANHÃ E DEPOIS. Nossa tarefa trabalhar a diferença disso. Hamlet e Hamlet-Máquina às vésperas da queda do muro de Berlim sete horas e meia de duração Hamletmachine diante das ruínas da Europa INTELECTUAL NO PÂNTANO DE SANGUE DAS IDEOLOGIAS DO SÉCULO revolução contra-revolução ARMADURA INFERNAL DO ESCLARECIMENTO Hamletmachine no turbilhão do acontecimento entre ruínas da TRAGÉDIA DO SÉCULO SOCIALISMO REAL e vestígios de uma EXPERIÊNCIA AURAL CAPITALISMO TOTAL scu intérprete UM CORO UM COLETIVO Hamlet-Máquina-social OFÉLIA/MEINHOFF/ELECTRA renega o mundo que pariu por sua EUROPA ventre com sêmen de dominantes dominados. Nossa tarefa trabalhar a diferença disso DESCOLONIZAÇÃO DA MENTE OS ÍNDIOS SABEM DO QUE SE TRATA. Tito Andrônico general e pai general versus pai ANATOMIA DA CARNE BRANCA pela faca nas mãos da carne moura e de seu amante mosca Aarão negro merda escravo que não implora pela vida Terceiro Mundo do Terceiro mundo enterrado para morrer E NADA LHE DÓI MAIS NO CORAÇÃO DO QUE NÃO PODER TER DISTRIBUÍDO MAIS DEZ MIL TERRORES DORES HORRORES. Cresce na terra RI BLACK do drama entre brancos e negros RI periferia da periferia. Nossa tarefa trabalhar a diferença disso DELETADOS drogados A HISTÓRIA ESTÁ GIRANDO POR ONDE NÃO SE ESPERA.

\section{REFERÊNCIA}

MÜLLER, Heiner. Quatro textos para teatro: Manser, Hamlet-máquina, A missão, Quarteto. Apresentação Fernando Peixoto. Trad. Fernando Peixoto e Reinaldo Mestrinel. São Paulo: Hucitec / Associação Cultural Bertolt Brecht, 1987.

Temáticas, Campinas, 18(35/36): 205-210, jan./dez. 2010 